\title{
Quality-by-Design Based Development and Validation of Stability Indicating Method by UPLC Method for Impurities of Simvastatin from Drug and Pharmaceutical Dosage Form
}

\author{
M. M. DESAI AND ANNA PRATIMA G. NIKALJE ${ }^{\text {* }}$ \\ Maulana Azad College of Arts and Science, Dr. Babasaheb Ambedkar Marathwada University, University Campus, \\ Aurangabad, Maharashtra 431004, ${ }^{1}$ Wilson College, Sea Facing, Mumbai, Maharashtra 400007, India
}

Desai et al.: QbD based UPLC method development for Simvastatin impurities

\begin{abstract}
A rapid, robust and accurate ultra-high performance liquid chromatographic method was developed and validated for determination of impurities of simvastatin in drug and its pharmaceutical formulation. A systematic Quality-by-design approach was used for method development with the Fusion $\mathbf{A E}^{\mathrm{TM}}$ software, to screen and optimize the column, mobile phase, column temperature, gradient time and other chromatographic conditions. The optimized method uses Waters Acquity Charged Surface Hybrid, Octadecylsilane $\mathrm{C} 18(1.7 \mu \mathrm{m} \times 2.1 \mathrm{~mm} \times 100 \mathrm{~mm})$ column with gradient elution. Orthophosphoric acid $\mathrm{pH}$ was adjusted to 4.5 with triethylamine and acetonitrile with a ratio of $(80: 20)$ was used as mobile phase $A$, whereas methanol:acetonitrile (20:80) as mobile phase $B$, with a flow rate of $0.35 \mathrm{ml} / \mathrm{min}$. Ultra Violet detector was programmed at $238 \mathrm{~nm}$ with a runtime of $13 \mathrm{~min}$, wherein all the impurities were well resolved and were separated from main peak of simvastatin. The method was validated for accuracy, repeatability, reproducibility and robustness. All the validation parameters were in acceptable range. The linearity, limit of detection and limit of quantitation was established for all the impurities and for simvastatin. The method was also applied suitably for determining the degradation products of simvastatin using stress degradation studies
\end{abstract}

Key words: Simvastatin, ultra-performance liquid chromatography, quality-by-design, stress degradation

The conventional approach for analytical method development involves changing one factor at a time (OFAT), commonly known as OFAT technique. The OFAT is very time consuming and lengthy process which generates voluminous data, resulting in a tedious approach. Also, once the method is developed, the method still may need additional efforts when validated $^{[1]}$. The modern pharmaceutical analysis and regulatory scenario, demands to use novel chemometric tools which control many variables simultaneously and helps to provide desired results with minimum experimental trials. This can be achieved by implementing Quality-by-Design (QbD) approach in analytical method development. In International Conference on Harmonization (ICH) guideline Q8(R2) for Pharmaceutical development, $\mathrm{QbD}$ is defined as " $\mathrm{A}$ systematic approach to development that begins with predefined objectives and emphasizes product and

*Address for correspondence E-mail: annapratimanikalje@gmail.com January-February 2021 process understanding and process control, based on sound science and quality risk management" ${ }^{[1,2]}$. The elements of QbD can be extended for analytical method development. The Analytical QbD utilizes statistical modeling and design of experiments (DoE) to arrive at a method operable design region (design space), the robust area, where the developed method provides the desired results ${ }^{[3]}$.

Simvastatin (SMV), chemically designated as $-(+\}-\{1 \mathrm{~S}$, 3R, 7S, 8S, 8aR)-1,2,3,7,8,8a-hexahydro-3,7-dimethyl8-[2-(2R,4R)-tetrahydro-4-hydroxy-6-oxo-2H-pyran-

This is an open access article distributed under the terms of the Creative Commons Attribution-NonCommercial-ShareAlike 3.0 License, which allows others to remix, tweak, and build upon the work non-commercially, as long as the author is credited and the new creations are licensed under the identical terms

Accepted 25 January 2021 Revised 15 November 2020 Received 12 May 2020 Indian J Pharm Sci 2021;83(1):110-119 
2-yl]-I-naphthyl-2, 2-dimethyl butanoate (fig. 1). It is a synthetic lipid lowering agent, which acts by inhibiting 3-hydroxy-3-methyl-glutaryl-coenzyme A (HMG $\mathrm{CoA}$ ) reductase and is widely used for the treatment of hypercholesterolemia. It has significantly reduced the morbidity and mortality related to the coronary heart disease. SMV is a prodrug and after oral administration it is converted into $\beta$ hydroxy acid of SMV, which is a potent inhibitor of HMG CoA reductase, a key enzyme used in the biosythesis of cholesterol in liver ${ }^{[4]}$.

SMV is official in United States Pharmacopeia (USP), British Pharmacopoeia (BP) and European Pharmacopoeia (Ph. Eur.), whereas SMV Tablets are official in BP and USP. SMV Impurity A, B, C, D, E, F and G (fig. 2) are specified in SMV Tablet monograph in BP as well as in USP. The analytical method followed for related substance test in SMV Tablets in both Pharmacopoeia is high performance liquid chromatography (HPLC) method of analysis ${ }^{[5-7]}$. The literature shows few methods for estimation of SMV along with its impurities are reported in the literature such as HPLC with Ultra-Violet detection ${ }^{[8-12]}$. The degradation behavior studies using ultra-high performance liquid chromatography (UHPLC)/Mass spectrometry (MS) is reported ${ }^{[1]}$. There are various stability indicating methods available for determination of SMV along with the other drugs and its degradation products $^{[13-17]}$. But these methods are either non-specific with respect to Pharmacopoeial impurities or having very long run time.

The analytical method development by using the QbD approach is a recent trend and very few manuscripts are published where the methods are developed using the analytical QbD. Also, various regulatory agencies are requesting that along with the product development, even the analytical methods shall be developed using

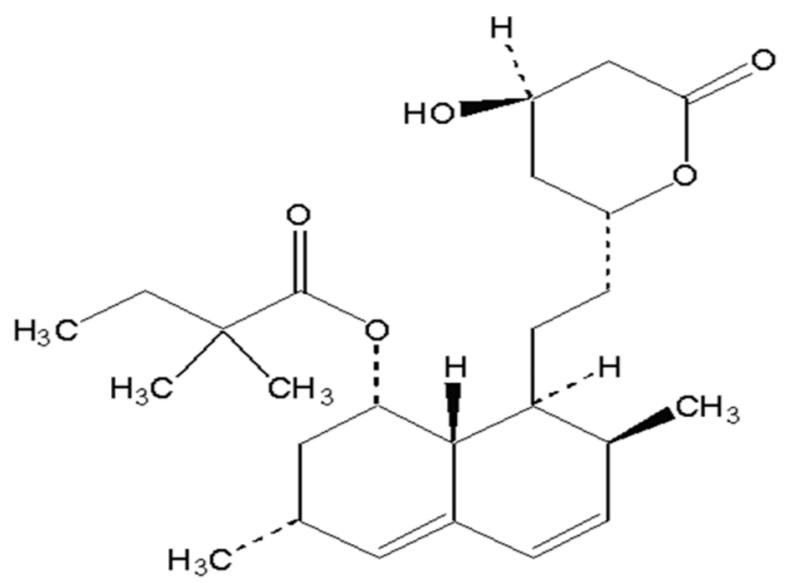

Fig. 1: Chemical structure of SMV the QbD approach. Hence, the present work was aimed at development of a specific, robust and validated method for estimation of SMV and its impurities using QbD approach and DoE principles. SMV is chosen as a model drug because of its great scientific interest due to low solubility and proven instability.

\section{MATERIALS AND METHODS}

SMV and its impurities (SMV Impurity A, B, C, D, E, $F$ and $G$ ) were obtained as gift sample from Ipca Laboratories Ltd., Mumbai, India. Acetonitrile (HPLC grade), methanol (HPLC grade), triethylamine (TEA) (for Chromatography) and orthophosphoric acid (OPA) $88 \%$ (Emparta ${ }^{\circledR}$ American Chemical Society (ACS)) was purchased from Merck Life Sciences Pvt. Ltd., Mumbai, India. Milli Q water, obtained from Millipore (Massachusetts, USA), was used in preparation of solutions. Buffers and all other chemicals were of analytical grade.

\section{Equipment:}

Experiments were performed on an Acquity ultra performance liquid chromatography (UPLC) H-Class System (Waters Corporation, Milford, Massachusetts) equipped with an autosampler, a quaternary gradient pump, a temperature controlled column compartment, photo-diode array detector and column selection valve. The UPLC system was also equipped with column switch. Instrument control and data acquisition were performed on Empower 2 Chromatography Software (Waters). The method development experiments were designed using Fusion AETM software (S-Matrix Corporation, Eureka, California (CA).

\section{Method:}

The method development studies were carried out in two phases. The first phase consists of the screening experiments wherein columns of different selectivity were used to find the best column which can offer the greatest possible separation of SMV and its impurities. Along with columns, aqueous mobile phases at different $\mathrm{pH}$, organic modifiers, and gradient time were also evaluated using systematic $\mathrm{QbD}$ design generated using Fusion $\mathrm{AE}^{\mathrm{TM}}$ software to obtained best and most robust separation with shortest run time.

In the second phase the best column, aqueous mobile phase with $\mathrm{pH} 4.5$ and organic solvent type were used for further method optimization to achieve the best chromatographic conditions. These selected parameters were kept constant and other chromatographic 
<smiles>CCC(C)(C)C(=O)O[C@H]1[C@H](C)C=C2C=C[C@H](C)[C@H](CC[C@H](O)CC(O)CC(=O)O)[C@]2(C)[C@H]1C</smiles>

Impurity A<smiles>CCC(C)(C)C(=O)O[C@H]1C[C@@H](C)C=C2C=C[C@H](C)[C@H](CC[C@@H]3CC=C[C@H](O)O3)[C@H]2[C@H]1C</smiles>

Impurity C

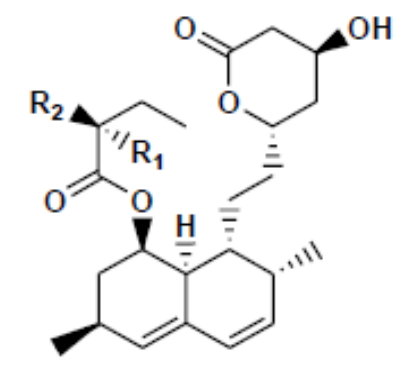

$\mathrm{R} 1=\mathrm{CH} 3, \mathrm{R} 2=\mathrm{H}$

Impurity $\mathbf{E}$<smiles>C=C1C=C2C=C[C@H](C)[C@H](CC[C@@H]3C[C@@H](O)CC(=O)O3)[C@H]2[C@H](OC(=O)C(C)(C)CC)C1</smiles>

Impurity $G$

Fig. 2: Impurities of SMV

parameters such as flow rate, gradient time and column oven temperature were studied to characterize their response effects and establish method performance region (design space).

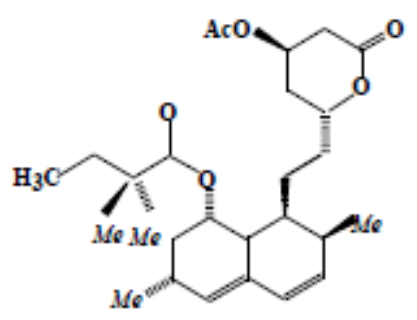

Impurity B

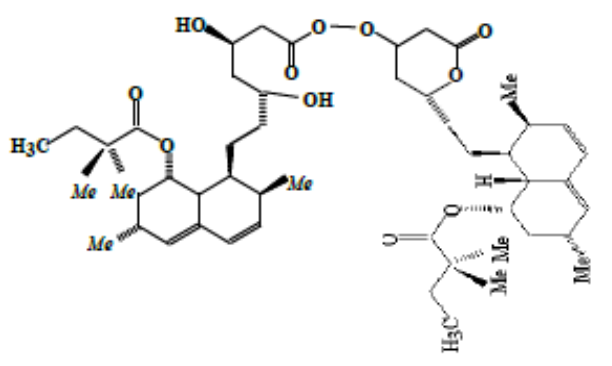

Impurity D

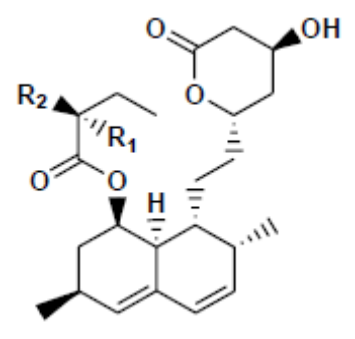

$\mathrm{R} 1=\mathrm{H}, \mathrm{R} 2=\mathrm{CH} 3$

Impurity $\mathbf{F}$ 
by mixing $400 \mathrm{ml}$ of the above buffer with $600 \mathrm{ml}$ of acetonitrile. The same buffer is used for mobile phase A preparation.

Preparation of standard solution: A stock solution was prepared by dissolving accurately weighed 50 mg of SMV to obtain $0.5 \mathrm{mg} / \mathrm{ml}$ solution using above mentioned diluent. The stock solution was further diluted with diluent to give $0.5 \mu \mathrm{g} / \mathrm{ml}$ solution.

Standard preparation: Tablets powder equivalent to $50 \mathrm{mg}$ of $\mathrm{SMV}$ is weighed and transferred to $100 \mathrm{ml}$ volumetric flask. About $70 \mathrm{ml}$ of diluent was added to the flask and sonication was done for about 20 min with intermittent shaking. Flask was cooled to room temperature and then filtered solution was used for analysis.

\section{Method validation:}

Method was validated on the following criteria: specificity, linearity, Limit of detection (LOD) and limit of quantitation (LOQ), precision, accuracy, robustness and stress degradation studies based on ICH guide lines (ICH Q2 (R1)).

Specificity: Specificity is the ability to unequivocally assess the analyte in the presence of other potential components, typically including impurities, degradants, matrix, etc. In order to determine the specificity of the method, the following solutions were injected: Diluent, placebo preparation, sample solution and individual impurity solution (Impurity A, B, C, D, E, F and G).

Linearity: In order to verify the linearity of the detector, a minimum of six concentration levels of each impurities corresponding to $5 \%$ to $150 \%$ of the specified value was performed. For Impurity $\mathrm{A}$, Impurity $\mathrm{C}$ and Impurity $\mathrm{D}, 0.10,0.20,0.50,1.00,2.00$ and $3.00 \mu \mathrm{g} / \mathrm{ml}$; for Impurity B and Impurity G, 0.05, 0.10, 0.20, 0.50, 1.00 and $1.50 \mu \mathrm{g} / \mathrm{ml}$; for Impurity E and F, 0.25, 050, $1.00,2.50,5.00$ and $7.50 \mu \mathrm{g} / \mathrm{ml}$; whereas, for SMV $0.025,0.05,0.10,0.25,0.50$ and $0.75 \mu \mathrm{g} / \mathrm{ml}$ were the concentration levels prepared and injected for linearity constructions.

Detection and quantitation limits: Limit of detection (LOD) and limit of quantitation (LOQ) were obtained from signal to noise ratio. The detection limit was defined as the lowest concentration level resulting in a peak area of three times the baseline noise. The quantitation limit was defined as the lowest concentration level that provided a peak area with a signal-to-noise ratio higher than 10 .

Accuracy of the method: The accuracy experiment was performed over the range of $50 \%, 100 \%$ and 150 $\%$ of the specification level of each impurity. Three samples at each concentration level were prepared and injected.

System precision: System Precision was determined from six replicate injections of the SMV standard solution $(0.5 \mu \mathrm{g} / \mathrm{ml})$. The acceptance criterion was \pm 2 $\%$ of coefficient of variation $(\% \mathrm{CV})$ for retention times and peak areas for both drugs.

Method precision (Repeatability): The repeatability of the method was evaluated by the analysis of impurities in the sample solution. Six sample preparations were performed and each one was injected once.

Intermediate precision: In order to evaluate the intermediate precision of the UPLC method, related compounds test, was analyzed on a different day, using a different preparation of mobile phase, a different UPLC system, a different column as well as a different analyst performing the analysis. The same batch of the tablets was used in this study for a comparison purpose.

Stress degradation studies: Stress testing of the drug product can help to identify the likely degradation products and specificity of the analytical procedures. The stress degradation of SMV tablets sample was conducted for hydrolytic degradation (acid and base treated) and oxidative degradation. For acid hydrolysis, $5 \mathrm{ml}$ of 0.5 Molar (M) hydrochloric acid solution was added to the sample and flask was kept in water bath at $60^{\circ}$ for $30 \mathrm{~min}$, whereas for base hydrolysis, $5 \mathrm{ml}$ of $0.1 \mathrm{M}$ hydrochloric acid solution was added to the sample and it was kept in at room temperature for 10 min. After treatment period the samples were suitably neutralized with corresponding base or acid and further sample preparation was followed as given above. For oxidative degradation, $5 \mathrm{ml}$ of $1 \%$ Hydrogen peroxide $\left(\mathrm{H}_{2} \mathrm{O}_{2}\right)$ solution was added to the sample and followed as above.

\section{RESULTS AND DISCUSSION}

Achieving best separation with fastest possible runtime with highest possible sensitivity was our goal during the method development. To achieve best separation among the impurities and SMV, choosing the right column 
with optimum selectivity is a key during development. After selection of right column, mobile phase $\mathrm{pH}$ and composition must be optimized to obtain the desired separation with shortest runtime without compromising selectivity and sensitivity of the method. The systematic approach of maximizing selectivity without compromising sensitivity is completely missing in the current literature for the development. The systematic approach of QbD uses more statistical concepts with experimental design plans (also referred as DoE) as an efficient and fast tool for method development which is achieved using Fusion $\mathrm{AE}^{\mathrm{TM}}$ software

In the first phase of method development, screening experiments were performed using the "Method screening" tool of Fusion AE ${ }^{\mathrm{TM}}$ software (S-Matrix Corporation, Eureka, CA). The screening of different chemistry for columns, selection of mobile phase $\mathrm{pH}$, selection of organic modifiers and gradient composition was studied using Method screening tool. The details of method variables are tabulated in Table 1.

Total 46 experiments were designed statistically using DoE principles. Few repeat trials were included in these designed experiments for statistical reason. Table 2 represents the experimental design used in the column and eluent combination scouting phase. The designed experiments were then exported to the chromatographic data software (Empower 2) as ready to run methods and sequence. This ready sequence was executed and data was generated in Empower 2 software on UPLC system. After completion of the sequence, the results were processed and selection of column, mobile phase $\mathrm{pH}$, organic modifier and gradient time was done with predetermined goal using the "Numerical search tool" in Fusion $\mathrm{AE}^{\mathrm{TM}}$ software. Not less than 6 peaks and not

TABLE 1: QbD METHOD VARIABLES

\begin{tabular}{lc}
\hline Study variables & Range or levels \\
\hline & Acquity UPLC Bridged Ethyl Hybrid (BEH) Amide, $100 \times 2.1 \mathrm{~mm}, 1.7 \mu \mathrm{m}$ \\
Column type & Acquity UPLC CSH C18, $100 \times 2.1 \mathrm{~mm}, 1.7 \mu \mathrm{m}$ \\
& Acquity UPLC High Strength Silica (HSS), $100 \times 2.1 \mathrm{~mm}, 1.8 \mu \mathrm{m}$ \\
$\mathrm{pH}$ of mobile phase & Acquity UPLC CSH Phenyl-Hexyl, $100 \times 2.1 \mathrm{~mm}, 1.7 \mu \mathrm{m}$ \\
Strong solvent/Organic modifier & $3.00,4.50,5.00,7.40$ \\
Gradient time (Min) & (Buffers prepared with $5 \mathrm{ml}$ OPA in $1000 \mathrm{ml}$ water and pH adjusted with TEA) \\
Acetonitrile, Methanol
\end{tabular}

TABLE 2: DESIGN OF EXPERIMENTS FOR SCREENING

\begin{tabular}{|c|c|c|c|c|c|c|c|c|c|}
\hline Run No. & Solvent & $\begin{array}{c}\text { Gradient } \\
\text { Time }\end{array}$ & $\mathrm{pH}$ & Column & Run No. & Solvent & $\begin{array}{c}\text { Gradient } \\
\text { Time }\end{array}$ & $\mathrm{pH}$ & Column \\
\hline 1 & Acetonitrile & 12 & 3.00 & BEH Amide & 24 & Acetonitrile & 12 & 7.40 & BEH Amide \\
\hline 2 & Acetonitrile & 12 & 3.00 & CSH C18 & 25 & Acetonitrile & 5 & 7.40 & BEH Amide \\
\hline 3 & Acetonitrile & 5 & 3.00 & CSH C18 & 26 & Methanol & 12 & 3.00 & CSH Phenyl-Hexyl \\
\hline 4 & Acetonitrile & 5 & 3.00 & CSH Phenyl-Hexyl & 27 & Methanol & 12 & 3.00 & HSS C18 \\
\hline 5 & Acetonitrile & 5 & 3.00 & CSH C18 & 28 & Methanol & 5 & 3.00 & HSS C18 \\
\hline 6 & Acetonitrile & 10.3 & 4.50 & HSS C18 & 29 & Methanol & 5 & 3.00 & BEH Amide \\
\hline 7 & Acetonitrile & 6.8 & 4.50 & BEH Amide & 30 & Methanol & 10.3 & 4.50 & BEH Amide \\
\hline 8 & Acetonitrile & 8.5 & 4.50 & CSH C18 & $31^{\circ}$ & Methanol & 8.5 & 5.00 & CSH Phenyl-Hexyl \\
\hline 9 & Acetonitrile & 8.5 & 4.50 & CSH Phenyl-Hexyl & 32 & Methanol & 8.5 & 5.00 & CSH C18 \\
\hline 10 & Acetonitrile & 8.5 & 5.00 & $\mathrm{CSH}$ C18 & 33 & Methanol & 8.5 & 5.00 & BEH Amide \\
\hline 11 & Acetonitrile & 5 & 5.00 & HSS C18 & 34 & Methanol & 8.5 & 5.00 & HSS C18 \\
\hline 12 & Acetonitrile & 12 & 5.00 & CSH Phenyl-Hexyl & 35 & Methanol & 8.5 & 5.00 & HSS C18 \\
\hline 13 & Acetonitrile & 8.5 & 5.00 & BEH Amide & 36 & Methanol & 8.5 & 5.00 & CSH Phenyl-Hexyl \\
\hline 14 & Acetonitrile & 8.5 & 5.00 & CSH C18 & 37 & Methanol & 8.5 & 5.00 & CSH C18 \\
\hline 15 & Acetonitrile & 8.5 & 5.00 & HSS C18 & 38 & Methanol & 10.3 & 5.00 & CSH C18 \\
\hline 16 & Acetonitrile & 8.5 & 5.00 & CSH Phenyl-Hexyl & 39 & Methanol & 5.0 & 5.00 & CSH Phenyl-Hexyl \\
\hline 17 & Acetonitrile & 8.5 & 5.00 & HSS C18 & 40 & Methanol & 8.5 & 5.00 & BEH Amide \\
\hline 18 & Acetonitrile & 8.5 & 5.00 & CSH Phenyl-Hexyl & 41 & Methanol & 12 & 7.40 & CSH C18 \\
\hline 19 & Acetonitrile & 8.5 & 5.00 & BEH Amide & 42 & Methanol & 12 & 7.40 & CSH Phenyl-Hexyl \\
\hline 20 & Acetonitrile & 12 & 7.40 & HSS C18 & 43 & Methanol & 5 & 7.40 & CSH C18 \\
\hline 21 & Acetonitrile & 5 & 7.40 & CSH Phenyl-Hexyl & 44 & Methanol & 12 & 7.40 & CSH Phenyl-Hexyl \\
\hline 22 & Acetonitrile & 8.5 & 7.40 & CSH C18 & 45 & Methanol & 5 & 7.40 & BEH Amide \\
\hline 23 & Acetonitrile & 12 & 7.40 & HSS C18 & 46 & Methanol & 5 & 7.40 & HSS C18 \\
\hline
\end{tabular}


more than 10 min for the last peak in the sequence were set as goal parameters. The numerical search resulted in 5 best possible answers out of which first answer with 0.96 probabilities (Table 3 ) was selected as model run for optimization. The optimum run gave $\mathrm{pH} 4.5$ (OPATEA) as buffer for mobile phase with acetonitrile as organic modifier on Acquity UPLC Charged Surface Hybrid $(\mathrm{CSH}) \mathrm{C} 18,100 \times 2.1 \mathrm{~mm}, 1.7 \mu \mathrm{m}$.

Few trials were taken for mobile phase composition optimization, which includes addition of $20 \%$ acetonitrile in buffer to avoid precipitation and inclusion of $20 \%$ methanol in acetonitrile for obtaining better polarity for separation.

The second phase optimization of method was done using "Method Optimization" tool of Fusion AE software. In the optimization experiments, $17 \mathrm{DoE}$ experiments were generated (Table 4) and effects of three study parameters; Pump Flow rate $(0.35$ 0.40 and $0.45 \mathrm{ml} / \mathrm{min}$ ), Gradient time (6.0, 7.5 and $9.0 \mathrm{~min})$ and column temperature $\left(30,35\right.$ and $\left.40^{\circ}\right)$; were simultaneously evaluated to assess the effects of these parameters on each of the five response variables. The five response variables are listed in Table 5. Column type, injection volume, mobile phase buffer (pH 4.5 TEA/OPA buffer:methanol 80:20) and organic modifier (acetonitrile:methanol 80:20) were kept constant. The designed optimization sequence was run on chromatographic data software that is Empower 2. After completion of sequence the chromatographic runs were processed and the results were imported in Fusion $\mathrm{AE}^{\mathrm{TM}}$ for further statistical evaluation.

This chromatographic data was processed with trend response in capabilities in Fusion $\mathrm{AE}^{\mathrm{TM}}$ and prediction equations (models) were generated automatically. These prediction equations quantitatively characterize the independent and interactive effects of the study parameters on each critical quality attributes (variables) included in the study. These equations then used to predict the method performance region (Design space) within the experimental region. The performance region generated for estimation of SMV and its impurities is given in fig. 3. The unshaded region represents the design space where all the performance parameters of the method are successfully met. Based on these results, the final chromatographic conditions are given in Table 6. Fig. 4 provides three dimensional plots showing the combined effect of variables such as gradient flow and pump flow rate on no of peaks and USP resolution of $\geq 1.5$ between all peaks. As we can see that when the gradient time and flow rate is increased there is negative relationship for the number of peaks obtained. The representative chromatogram of sample solution in the optimized method is given as fig. 5 .

The developed method was then validated as per ICH Q2 (R2) guidelines. The validation results are discussed in details in following sections. The method specificity was proved by injecting the placebo solution, each individual impurity and standard solution and sample solution. All the impurities and the placebo peaks were very well separated from the main peak of SMV and all the impurities were well separated from each other (fig. 5). In addition, the peaks of impurities and SMV were found to be pure by peak purity analysis using Empower 2 software.

The calibration curves constructed for SMV and its impurities (A, B, C, D, E, F and G) were evaluated by its correlation coefficient. The peak area was found linear in the range of $5 \%$ to $150 \%$ of the specification levels as given in Table 7 . The correlation coefficients for all the calibration plots of SMV and its impurities were more than 0.999 .

The LOD and LOQ values were obtained from the linearity curve as per ICH guidelines and values are

TABLE 3: NUMERICAL ANSWER SEARCH

\begin{tabular}{|c|c|c|c|c|c|}
\hline \multicolumn{6}{|c|}{ Variable Settings } \\
\hline Variable & & \multicolumn{4}{|c|}{ Level Setting } \\
\hline Strong Solvent Type & & \multicolumn{4}{|c|}{ Acetonitrile } \\
\hline Gradient Type & & \multicolumn{4}{|c|}{12.00} \\
\hline $\mathrm{pH}$ & & \multicolumn{4}{|c|}{4.50} \\
\hline Column Type & & \multicolumn{4}{|c|}{ CSH C18 10 Column } \\
\hline \multicolumn{6}{|c|}{ Predicted results } \\
\hline Response & Goal & Predicted result & Desirability & $\begin{array}{c}-2 \text { Sigma Configuration } \\
\text { limit }\end{array}$ & $\begin{array}{c}+2 \text { Sigma Configuration } \\
\text { limit }\end{array}$ \\
\hline No. of Peaks & Maximize & 8.3 & 1.0000 & 7.2 & 10.0 \\
\hline $\begin{array}{l}\text { Last Peak-Retention } \\
\text { Time }\end{array}$ & Minimize & 9.09 & 1.0000 & 6.43 & 12.91 \\
\hline
\end{tabular}

Cumulative desirability target $=1.0000$, Cumulative desirability result $=1.0000$ 
represented in Table 7. The obtained LOQ values were found to be less than $20 \%$ of the specification level.

Accuracy for SMV and its impurities was determined by spiking known amount of analyte into formulation placebo at $50 \%, 100 \%$ and $150 \%$ levels. Triplicate spikes were performed for all levels. The results are summarized in Table 8 and met the acceptance criteria.

\section{TABLE 4: DESIGN OF EXPERIMENTS FOR} OPTIMIZATION

\begin{tabular}{lccc}
\hline Run No. & $\begin{array}{c}\text { Pump flow } \\
\text { rate }(\mathbf{m l} / \mathrm{min})\end{array}$ & $\begin{array}{c}\text { Gradient time } \\
(\min )\end{array}$ & Oven temp $\left(^{\circ}\right)$ \\
\hline 1 & 0.350 & 6.0 & 30.0 \\
2 & 0.450 & 6.0 & 30.0 \\
3 & 0.350 & 9.0 & 30.0 \\
4 & 0.450 & 9.0 & 30.0 \\
5 & 0.400 & 7.5 & 30.0 \\
6 & 0.450 & 7.5 & 35.0 \\
7 & 0.400 & 6.0 & 35.0 \\
8 & 0.400 & 9.0 & 35.0 \\
9 & 0.350 & 7.5 & 35.0 \\
10 & 0.400 & 7.5 & 35.0 \\
11 & 0.400 & 7.5 & 35.0 \\
12 & 0.400 & 7.5 & 35.0 \\
13 & 0.350 & 6.0 & 40.0 \\
14 & 0.400 & 7.5 & 40.0 \\
15 & 0.450 & 6.0 & 40.0 \\
16 & 0.350 & 9.0 & 40.0 \\
17 & 0.450 & 9.0 & 40.0 \\
\hline
\end{tabular}

The coefficient of variation of six replicate injections of the standard solution was found to be $0.37 \%$ which is well within the acceptance criteria. The coefficient of variation of peak area was within the range of $2 \%$ limit signifying suitability of the system.

The six sample preparations showed the coefficient of variance with in the acceptance criteria of less than $10 \%$ for all the impurities indicating that the method

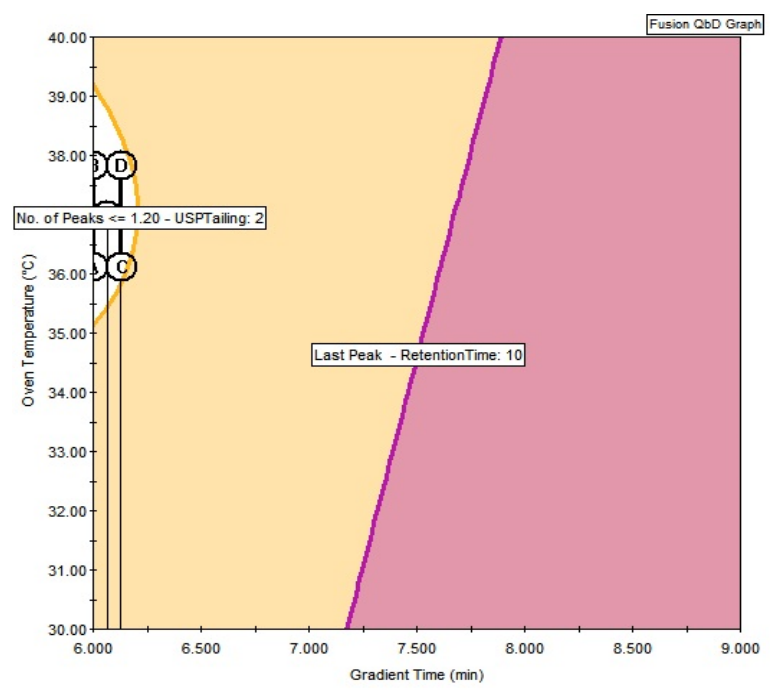

Fig. 3: Method performance region.

The unshaded region represents the design space where all the performance parameters of the method are successfully met

TABLE 5: RESPONSE GOAL SETTINGS

\begin{tabular}{|c|c|c|c|c|}
\hline Response & Target & Lower bound & Upper bound & Relative rank \\
\hline No. of peaks & Maximize & 6.0 & 9.0 & 1 \\
\hline No. of peaks $>=1.50$-USP resolution & Maximize & 1.0 & 2.0 & 1 \\
\hline No. of peaks $>=2.00-$ USP resolution & Maximize & 2.0 & 9.0 & 1 \\
\hline No. of Peaks $<=1.20$-USP tailing & Minimize & 1 & 9.0 & 1 \\
\hline Max Peak \#1-USP resolution & Maximize & 1.00 & 2.00 & 1 \\
\hline Last Peak-Retention time & Minimize & 7.00 & 10.00 & 1 \\
\hline
\end{tabular}

TABLE 6: OPTIMIZED CHROMATOGRAPHIC CONDITIONS FOR ANALYSIS OF SMV AND ITS IMPURITIES

\begin{tabular}{|c|c|c|c|}
\hline Parameters & \multicolumn{3}{|c|}{ Condition } \\
\hline$\overline{\text { Column }}$ & \multicolumn{3}{|c|}{ Waters Acquity CSH C18 $1.7 \mu \mathrm{m}, 2.1 \mathrm{~mm} \times 100 \mathrm{~mm}$} \\
\hline Flow rate & \multicolumn{3}{|c|}{$0.35 \mathrm{ml} / \mathrm{min}$} \\
\hline Column temperature & \multicolumn{3}{|c|}{$35^{\circ}$} \\
\hline Sampler temperature & \multicolumn{3}{|c|}{$10^{\circ}$} \\
\hline Injection volume & \multicolumn{3}{|c|}{$2 \mu \mathrm{l}$} \\
\hline Detector wavelength & \multicolumn{3}{|c|}{ UV, $238 \mathrm{~nm}$} \\
\hline Run time & \multicolumn{3}{|c|}{$13 \mathrm{~min}$} \\
\hline Diluent & \multicolumn{3}{|c|}{ Buffer:Acetonitrile $(40: 60 \mathrm{v} / \mathrm{v})$} \\
\hline \multirow{6}{*}{ Gradient Program } & Time & Mobile phase $\mathrm{A}$ & Mobile phase $B$ \\
\hline & 0 & 50 & 50 \\
\hline & 6.2 & 5 & 95 \\
\hline & 8.7 & 5 & 95 \\
\hline & 9.0 & 50 & 50 \\
\hline & 13.0 & 50 & 50 \\
\hline
\end{tabular}

Where, mobile phase A is buffer:acetonitrile (80:20) and mobile phase B is acetonitrile:methanol (80:20) 


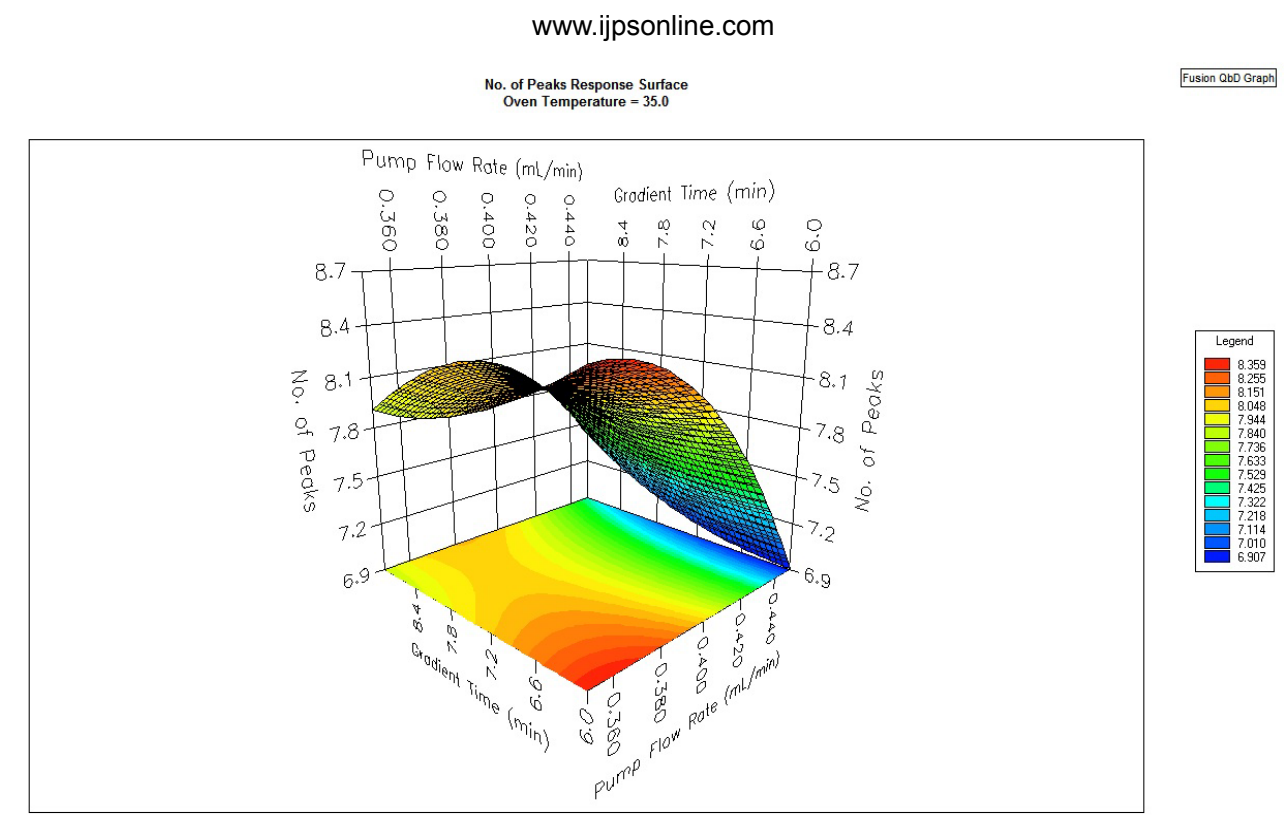

a)

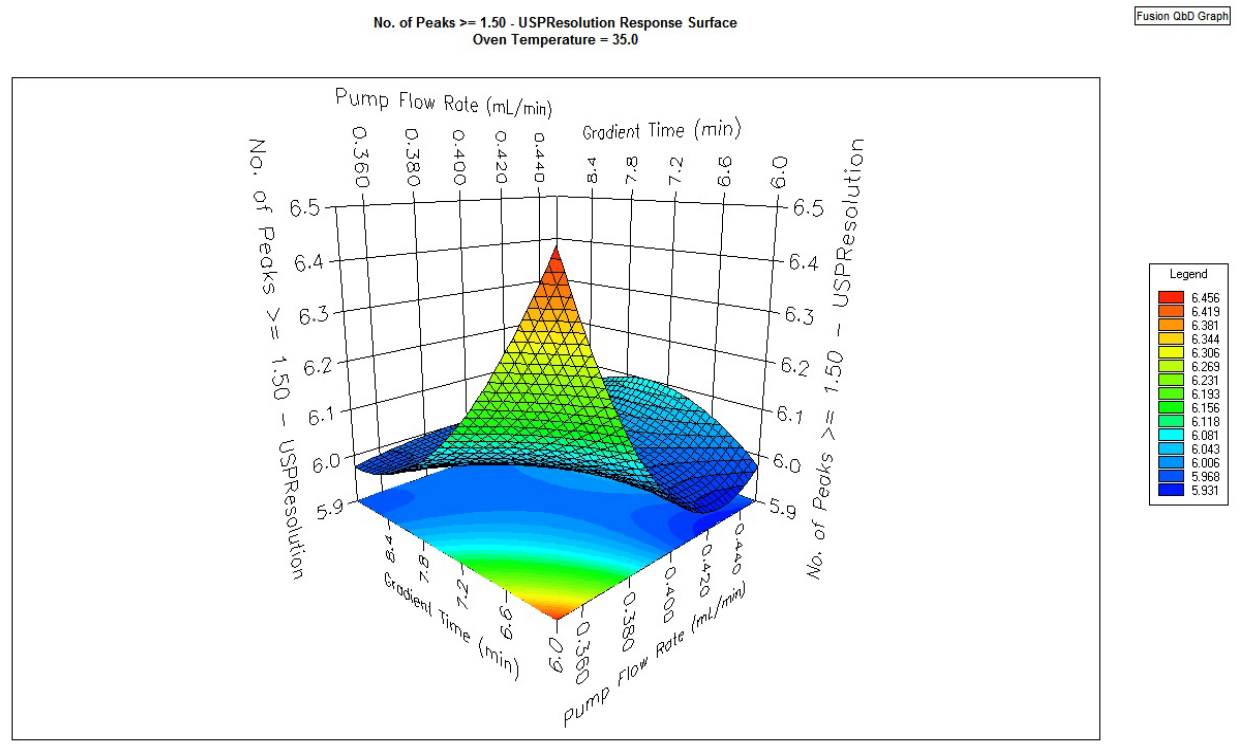

b)

Fig. 4: Three dimensional response surface plots.

(a) Correlation of No. peaks, (b) Correlation of USP resolution $>=1.5$

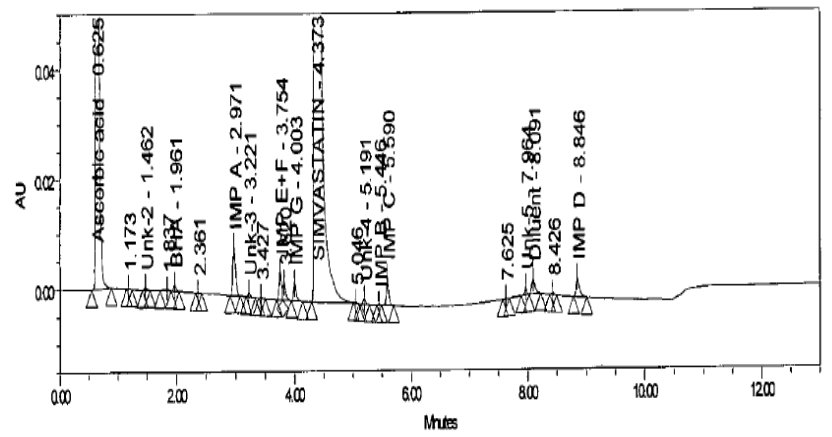

Fig. 5: Representative sample chromatogram of the optimized method

All impurities of SMV are well separated from main peak and from each other 
TABLE 7: METHOD SPECIFICITY, LINEARITY, LOD AND LOQ

\begin{tabular}{lcccccc}
\hline Component & RT & RRT & Equation & $\begin{array}{c}\text { Correlation } \\
\text { Coefficient }\end{array}$ & $\begin{array}{c}\text { Limit of } \\
\text { Quantification (\%) }\end{array}$ & $\begin{array}{c}\text { Limit of Detection } \\
\text { (\%) }\end{array}$ \\
\hline SMV & 4.389 & 1.00 & $\mathrm{y}=20166 \times-89.725$ & 1.0000 & 0.003 & 0.001 \\
Impurity A & 2.887 & 0.66 & $\mathrm{y}=7413 \mathrm{x}-143.39$ & 0.9999 & 0.034 & 0.011 \\
Impurity B & 5.468 & 1.25 & $\mathrm{y}=16235 \mathrm{x}-83.168$ & 0.9999 & 0.012 & 0.004 \\
Impurity C & 5.611 & 1.28 & $\mathrm{y}=17118 \mathrm{x}-234.68$ & 0.9998 & 0.033 & 0.011 \\
Impurity D & 8.836 & 2.01 & $\mathrm{y}=9386.1 \mathrm{x}-710.72$ & 0.9991 & 0.079 & 0.028 \\
Impurity E & 3.754 & 0.85 & $\mathrm{y}=20206 \mathrm{x}-365.72$ & 0.9999 & 0.054 & 0.018 \\
Impurity F & 3.820 & 0.87 & $\mathrm{y}=20377 \mathrm{x}-461.93$ & 0.9999 & 0.067 & 0.022 \\
Impurity G & 4.020 & 0.92 & $\mathrm{y}=18123 \mathrm{x}-83.198$ & 0.9999 & 0.011 & 0.003 \\
\hline
\end{tabular}

TABLE 8: ACCURACY AND PRECISION DATA

\begin{tabular}{lccccccc}
\hline \multirow{2}{*}{ Component name } & \multicolumn{3}{c}{ Mean recovery } & \multicolumn{2}{c}{ Method precision } & \multicolumn{2}{c}{ Intermediate precision } \\
\cline { 2 - 7 } & $\mathbf{5 0} \%$ & $\mathbf{1 0 0} \%$ & $\mathbf{1 5 0} \%$ & Analyst I & \% RSD & Analyst II & \% RSD \\
\hline SMV & 100.1 & 99.4 & 101.8 & - & - & - & 0.322 \\
Impurity A & 102.7 & 104.9 & 103 & 0.319 & 0.86 & 0.75 \\
Impurity B & 104.3 & 102 & 98.3 & 0.277 & 0.19 & 0.276 & 0.76 \\
Impurity C & 104.8 & 106.2 & 106.1 & 0.206 & 0.91 & 0.206 & 0.91 \\
Impurity D & 99.3 & 96.8 & 98.2 & 0.660 & 0.10 & 0.664 & 1.95 \\
Impurity E & 102.3 & 102.1 & 102.5 & 0.391 & 0.70 & 0.394 & 1.78 \\
Impurity F & 101.5 & 102.2 & 102.9 & 0.260 & 1.02 & 0.263 & 1.97 \\
Impurity G & 101.4 & 101.8 & 98.3 & 0.302 & 0.44 & 0.302 & 0.36 \\
Unknown Max & - & - & - & 0.048 & 1.56 & 0.048 & 1.07 \\
Total Impurity & - & - & - & 2.540 & 0.75 & 2.547 & 1.15 \\
\hline
\end{tabular}

TABLE 9: STRESS DEGRADATION STUDIES

\begin{tabular}{lcccc}
\hline \multirow{2}{*}{ Condition } & \multicolumn{3}{c}{ \% Impurity } \\
\cline { 2 - 5 } & As such & Acid & Base & Peroxide \\
\hline Impurity A & 0.455 & 23.26 & 0.565 & 0.451 \\
Impurity B & 0.007 & 0.007 & 0.008 & 0.007 \\
Impurity C & 0.365 & 0.379 & 0.344 & 0.345 \\
Impurity D & 0.422 & 0.356 & 0.419 & 0.42 \\
Impurity E & 0.399 & 0.334 & 0.396 & 0.398 \\
Impurity F & 0.263 & 0.259 & 0.273 & 0.264 \\
Impurity G & 0.116 & 0.097 & 0.114 & 0.115 \\
Unknown Max & 0.038 & 0.042 & 0.038 & 0.038 \\
Total & 2.329 & 26.985 & 2.409 & 2.501 \\
\hline
\end{tabular}

the known impurities were found to be pure. All the mass balance study showed results of more than $99 \%$ indicate that a good correlation was observed between generation of impurities in the degradation sample and the assay value of the sample. Hence it can be confirmed that no other peaks were obtained during stress degradation studies except for Impurity A which is a known degradation product of SMV.

In conclusion, a simple and rapid reversed-phase UPLC method has been developed systematically for estimation of SMV impurities using Fusion $\mathrm{AE}^{\mathrm{TM}}$ method development software. Response surface plots illustrated the major effects of gradient time flow rate and oven temperature on the separation. This method has been successfully validated for determination of SMV impurities from drug formulation. The QbD approach of method development is recommended by Food and Drug Administration (FDA) and provides a very clear picture of the robustness during the method development process. Unlike OFAT approach, it is a faster way of developing method, which helps choosing much better method condition during the development process through design space. The validation results confirmed the usefulness of the method. The method was found to be precise, accurate and linear, whereas the stress degradation studies identified the potential degradation products which can form during the shelf life of the product. This newly developed method is 
having run time of about 13 min which is almost 5-8 times shorter than the Pharmacopoeial and literature methods.

\section{Acknowledgement:}

None

\section{Conflict of interests:}

The authors declared no conflict of interest.

\section{REFERENCES}

1. Hadzieva Gigovska M, Petkovska A, Acevska J, Nakov N, Antovska P, Ugarkovic S, et al. Comprehensive assessment of degradation behavior of simvastatin by UHPLC/MS method, employing experimental design methodology. Int J Anal Chem 2018;7170539:1-17.

2. Pharmaceutical Development Q8 (R2), International Conference on Harmonisation (ICH), Geneva, Switzerland; 2009.

3. Karmarkar S, Garber R, Genchanok Y, George S, Yang X, Hammond R. Quality by design (QbD) based development of a stability indicating HPLC method for drug and impurities. J Chromatogr Sci 2011;49(6):439-46.

4. Patil P, Patil V, Paradkar A. Formulation of a self-emulsifying system for oral delivery of simvastatin: in vitro and in vivo evaluation. Acta Pharm 2007;57(1):111-22.

5. Simvastatin Monograph. In, the United States Pharmacopoeia, 42nd Rev. and the National Formulary, 37th ed. Rockville: United States Pharmacopoeial Convention Inc.; 2019. p. 400811.

6. Simvastatin Monograph. In, European Pharmacopoeia, 9.0. Strasbourg: European directorate for the quality of medicines and healthcare; 2019. p. 3554-5.

7. Simvastatin monograph. In, British Pharmacopoeia, 2019. London: The Stationary Office, British Pharmacopoeia Commission Office; 2019. p. 1230-1.
8. Sankar DG, Kondaveni R, Raju TR, Krishna MV. Gradient stability indicating RP-HPLC method for impurity profiling of simvastatin in tablet dosage forms. Asian J Org Chem 2009;21(6):4294-300.

9. Krishna SR, Deshpande GR, Rao BM, Rao NS. A Stability indicating RP-LC method for the determination of Related Substances in Simvastatin. J Chem Pharm Res 2010;2(1):91-9.

10. El Karbane M, Azougagh M, AL-Kamarany MA, Bouchafra $\mathrm{H}$, Cherrah Y, Bouklouze A. Development and validation of a reversed-phase HPLC method for simultaneous analysis of butylhydroxyanisol, simvastatin and its impurities in tablet dosage forms. Ann Pharm Fr 2014; 72(4):244-255.

11. Draghici IO, Arama CO, Nedelcu AN, Monciu CM, Stanescu MI, Tuchila CR. Development of a new LC method for the identification, separation and assay of simvastatin and its impurities. Farmacia 2013;61(2):229-39.

12. Malenovic A, Medenica M, Ivanovic D, Jancic B. Monitoring of simvastatin impurities by HPLC with microemulsion eluents. Chromatographia 2006;63(13):S95-100.

13. Desai PR, Mehta PJ, Ojha SK, Chokshi AB. Simultaneous quantification of related substances of ezetimibe and simvastatin in combined dosage form using a novel stabilityindicating liquid chromatographic method. Acta Chromatogr 2018;30(2):85-94.

14. Dixit RP, Barhate CR, Padhye SG, Viswanathan CL, Nagarsenker MS. Stability indicating RP-HPLC method for simultaneous determination of simvastatin and ezetimibe from tablet dosage form. Indian J Pharm Sci 2010;72(2):204-10.

15. Guzik L, Mrozik W, Kamysz W. Determination of simvastatin in pharmaceutical dosage forms by optimized and validated method using HPLC/UV. Croat Chem Acta 2010;83(4):371-7.

16. Nalaiya J, Sagineedu SR, Rajasingam R, Kassim Z, Pichika MR. A stability-indicating RP-HPLC method for simultaneous determination of simvastatin and niacin in a combined dosage form. Int J Pharm Pharm Sci 2015;7(2):262-8.

17. Sawant $S$, Ghante M. A validated stability indicating RP-HPLC method for Simvastatin, identification and characterization of forced degradation products of Simvastatin using LC-ESI-MS/ MS. Adv Anal Chem 2015;5(1):8-16. 